\title{
Numerical Modeling and Investigation on Aerodynamic Noise Characteristics of Pantographs in High-Speed Trains
}

\author{
Xiaoqi Sun ${ }^{1}$ and Han Xiao $\mathbb{D}^{2}$ \\ ${ }^{1}$ School of Mathematics and Statistics, Qingdao University, Qingdao, China \\ ${ }^{2}$ School of Mathematical Sciences, Ocean University of China, Qingdao, China \\ Correspondence should be addressed to Han Xiao; hxiao@ouc.edu.cn
}

Received 24 December 2017; Revised 1 February 2018; Accepted 10 February 2018; Published 20 March 2018

Academic Editor: Changzhi Wu

Copyright (c) 2018 Xiaoqi Sun and Han Xiao. This is an open access article distributed under the Creative Commons Attribution License, which permits unrestricted use, distribution, and reproduction in any medium, provided the original work is properly cited.

\begin{abstract}
Pantographs are important devices on high-speed trains. When a train runs at a high speed, concave and convex parts of the train cause serious airflow disturbances and result in flow separation, eddy shedding, and breakdown. A strong fluctuation pressure field will be caused and transformed into aerodynamic noises. When high-speed trains reach $300 \mathrm{~km} / \mathrm{h}$, aerodynamic noises become the main noise source. Aerodynamic noises of pantographs occupy a large proportion in far-field aerodynamic noises of the whole train. Therefore, the problem of aerodynamic noises for pantographs is outstanding among many aerodynamics problems. This paper applies Detached Eddy Simulation (DES) to conducting numerical simulations of flow fields around pantographs of highspeed trains which run in the open air. Time-domain characteristics, frequency-domain characteristics, and unsteady flow fields of aerodynamic noises for pantographs are obtained. The acoustic boundary element method is used to study noise radiation characteristics of pantographs. Results indicate that eddies with different rotation directions and different scales are in regions such as pantograph heads, hinge joints, bottom frames, and insulators, while larger eddies are on pantograph heads and bottom frames. These eddies affect fluctuation pressures of pantographs to form aerodynamic noise sources. Slide plates, pantograph heads, balance rods, insulators, bottom frames, and push rods are the main aerodynamic noise source of pantographs. Radiated energies of pantographs are mainly in mid-frequency and high-frequency bands. In high-frequency bands, the far-field aerodynamic noise of pantographs is mainly contributed by the pantograph head. Single-frequency noises are in the far-field aerodynamic noise of pantographs, where main frequencies are $293 \mathrm{~Hz}, 586 \mathrm{~Hz}, 880 \mathrm{~Hz}$, and $1173 \mathrm{~Hz}$. The farther the observed point is from the noise source, the faster the sound pressure attenuation will be. When the distance of two adjacent observed points is increased by double, the attenuation amplitude of sound pressure levels for pantographs is around $6.6 \mathrm{~dB}$.
\end{abstract}

\section{Introduction}

With the rapid development of high-speed trains, the running speed of trains is increased continuously, and train bodies are developed towards a lighter weight. Meanwhile, aerodynamic problems caused by high-speed trains become more and more significant. Especially, aerodynamic problems of pantographs have drawn immediate attention of scientific researchers.

Pantographs are an important device on the top of highspeed trains. When a train runs at a high speed, concave and convex parts on the train will cause serious disturbance on airflows and make them generate complicated flow separation, eddy shedding, and breakdown. As a result, a strong fluctuation pressure field will be caused and transformed into aerodynamic noises [1]. Studied results indicate that when the running speed of high-speed trains reaches $300 \mathrm{~km} / \mathrm{h}$, aerodynamic noises will be more than wheel-rail noises, becoming the main noise source. Aerodynamic noises of pantographs occupy a very large proportion in far-field aerodynamic noises of the complete train $[2,3]$. At present, the running speeds of trains on some tracks have reached $350 \mathrm{~km} / \mathrm{h}$. Aerodynamic noises of trains not only cause noise pollution in trains, but also reduce passenger comfort and seriously affect life of residents along the track [4]. Aerodynamic noises of trains are a key factor 
for suppressing the increase of running speed. Designed and experimental speeds of the Japanese Shinkansen train are more than $350 \mathrm{~km} / \mathrm{h}$. However, the aerodynamic noise level reaches an oppressive level. Finally, trains of this series can only run at $300 \mathrm{~km} / \mathrm{h}$. And the designed speed of Shanghai maglev trains is more than $430 \mathrm{~km} / \mathrm{h}$. Limited by the noise standard, trains can only run under $200 \mathrm{~km} / \mathrm{h}[5,6]$.

At present, researches on aerodynamic noises of pantographs are relatively underdeveloped compared with researches on the complete train structure and system. Researches on aerodynamic noises of pantographs are mainly completed by experimental test and numerical simulation. Experimental tests are divided into wind tunnel tests and full-scale model with real trains. Noger et al. [7] tested aerodynamic noises of the TGV pantograph system using wind tunnels, finding that the perpendicular face on the back of pantographs was one of the most important aerodynamic noise sources. Kitagawa and Nagakura $[8,9]$ tested aerodynamic noises of high-speed trains using wind tunnel and real-train tests, finding that aerodynamic noise sources included pantographs, bogies, nose tips, pilots, train heads, train tails, train connectors, and skirt plates. Mellet et al. [1] used the real-train experiment to test aerodynamic noises outside trains, finding that sound pressure levels of far-field aerodynamic noises were in approximate linear relation with the logarithm of running speed, and the contribution of pantographs to the total far-field noise ranked the second position. Gao et al. [10] used the wind tunnel test to study aerodynamic noises of high-speed trains with scaled ratio of $1: 8$, finding that noises of bogies and pantographs are major noise sources of the model, and the pantograph had large noise energies at $500 \mathrm{~Hz} \sim 800 \mathrm{~Hz}, 2 \sim 4 \mathrm{kHz}$, and $6 \mathrm{kHz}$. In respect of numerical researches, combining computational fluid dynamics with computational acoustics was used to study aerodynamic noises, noise generation mechanism, and noise radiation characteristics of high-speed trains or main components (such as bogies, pantographs, and joints). King III [11] equalized the pantograph as a cylinder and used a dipole sound source to describe aerodynamic noises induced by cylinder eddy shedding, further analyzing farfield aerodynamic noise of pantographs and pointing out that sound pressures of pantographs were in direct proportion to the sixth power of the running speed, while the sound pressure level was in linear relation with the logarithm of the running speed. Liu et al. [12] adopted a hybrid method which obtained an equivalent aerodynamic noise source using large eddy simulation and then loaded the source on acoustic boundary elements. Characteristics of dipole noise sources on the surface of single-arm pantographs were studied in detail. Studied results indicate that main energies of the single-arm pantograph were concentrated within $100 \sim 700 \mathrm{~Hz}$. When the running speed was stable, with the increased frequency, the amplitude of dipole noise source on the surface of pantographs would be decreased. When the frequency was increased from $20 \mathrm{~Hz}$ to $5000 \mathrm{~Hz}$, the amplitude of dipole noise source under different running speeds was decreased by $30 \mathrm{~dB}$. Du et al. [13] conducted a numerical analysis on aerodynamic noises of pantographs. Analyzed results indicate that carbon slide plate was a major control factor in aerodynamic noses, while the bottom frame structure was the second factor. In order to reduce aerodynamic noises of the pantograph, Ikeda et al. [14] adopted porous materials to pantographs and proposed a novel pantograph, achieving obvious noise reduction effects. Xiao and Shi [15] conducted a simulation computation for different cross section shapes of pantograph insulators. They found that insulators with elliptic cross sections whose long axis consists with the airflow direction are optimal. Yu et al. [16] designed three kinds of pantograph guide guards and conducted a noise reduction analysis based on opened running mode of pantographs, finding that noise reduction effects were obvious and sound pressure levels were decreased by $3 \mathrm{~dB}$ adopting this pantograph guide guard similar to air barriers.

In those published papers, just using wind tunnel or real-train tests has a high cost and low efficiency, while the repeatability of experimental results is poor. The problem has been solved very effectively by the reported numerical simulation. However, most researches fail to verify the numerical model using experimental test, and the reliability of studied results cannot be ensured. The approach of noise numerical simulation mainly depends on acoustic analogy theory and cannot conduct systematic researches on noise radiation characteristics. Aiming at these problems, this paper conducted an in-depth research on generation mechanism, sources, and radiation characteristics of aerodynamic noises for pantographs based on acoustic analogy theory and boundary element method. The reliability of numerical models is also verified by experimental test. Studied results prove that, in high-frequency bands, the far-field aerodynamic noise of pantographs is mainly contributed by the pantograph head. Single-frequency noises are in the far-field aerodynamic noise of pantographs, where main frequencies are $293 \mathrm{~Hz}, 586 \mathrm{~Hz}, 880 \mathrm{~Hz}$, and $1173 \mathrm{~Hz}$.

\section{Acoustic Analogy Theory}

With the development of computer technologies, computational aeroacoustics have gradually developed into an important tool which explores aerodynamic noise mechanism, finds noise source positions, and predicts noises. The method of combining CFD and acoustic analog theory [17] (FW$\mathrm{H}$ equation [18] and free space green function) is the most popular aerodynamic noise prediction method in current engineering applications. The basic idea divides computation of sound fields into two steps: firstly, CFD is used to compute near-field parts, and sound source information data is obtained; then, acoustic analog theory is used to solve propagation of sound waves from near field to far field.

Aerodynamic noises are the result of interactions between fluid and structure when fluids flow through the solid surface. As universal fluid software, Fluent integrates strong computation ability for aerodynamic noises. By solving fluid dynamics equations, Fluent can directly achieve generation and propagation of acoustic waves. The direct computation method is called CAA (Computational Aero Acoustics). Viscidity and turbulence effects are simulated accurately through directly solving nonsteady N-S equations and Reynolds 
average RANS equations [19-21]. CAA method requires a numerical solution method with high precision, refined meshes, and nonreflective boundary conditions, so that the computational cost is very high. At present, the method cannot be used to solve aerodynamic noise problems of high-speed trains. Another computation method in Fluent is the Lighthill acoustic analogy which is widely used and can also be called AAA (Aero-Acoustic Analogy) method [22-24]. Different from CAA method, "acoustic analogy" method decouples wave equations and flow equations. A nonsteady flow equation is solved at first. Then, solved results are taken as a noise source. An acoustic wave solution is solved by a wave equation. In this way, the acoustic wave solution is detached from flowing solution process, so that the computational efficiency is improved, and complicated aerodynamic acoustic problems can be solved. Based on mass conservation and momentum conservation equations, Lighthill obtained a wave equation of aerodynamic noises generated from turbulent flows with a small scale enclosed by static fluids, as follows:

$$
\frac{\partial^{2} \rho^{\prime}}{\partial \tau^{2}}-c_{0}^{2} \nabla^{2} \rho^{\prime}=\frac{\partial^{2} T_{i j}}{\partial y_{i} \partial y_{j}},
$$

where $\rho^{\prime}$ is the disturbance quantity of fluid density, $\rho^{\prime}=$ $\rho-\rho_{o}$, and $\rho$ and $\rho_{o}$ are density before and after disturbance; $T_{i j}$ is the Lighthill stress, and $T_{i j}=\rho u_{i} u_{j}-e_{i j}+\delta_{i j}(p-$ $\left.c_{0} \rho\right) ; e_{i j}$ is the viscosity stress; $\delta_{i j}$ is the symbol of Kronecker delta; $c_{o}$ is sound velocity. The left end of (1) is the same with those of common acoustic equations, and the right end is equivalent to a sound source item. In fact, the right end of (1) contains a variable $\rho$, so (1) is not an acoustic wave equation in fact. Essentially, it is still a fluid flow equation. As pointed out by Lighthill, if the right end of equation is deemed as a quadrupole source item, (1) will become a typical acoustic wave equation, and the method can be called "acoustic analogy" method.

Based on the Lighthill equation, FW-H (Ffowcs Williams and Hawkings) applied the generalized Green function to generalize the Lighthill acoustic analogy theory into a flow noise issue with arbitrary solid boundaries, obtaining a FW-H equation which is widely applied at present [18]. The equation is as follows:

$$
\begin{aligned}
& \left(\frac{1}{c_{0}^{2}} \frac{\partial^{2}}{\partial t^{2}}-\nabla^{2}\right)\left(H c_{0}^{2}\left(\rho-\rho_{0}\right)\right) \\
& =\frac{\partial^{2}\left(H T_{i j}\right)}{\partial x_{i} \partial x_{j}}-\frac{\partial}{\partial x_{i}}\left(\left(\rho v_{i}\left(v_{j}-u_{j}\right)+p_{i j}\right) \frac{\partial H}{\partial x_{j}}\right) \\
& \quad+\frac{\partial}{\partial t}\left(\left(\rho\left(v_{j}-u_{j}\right)+\rho_{0} u_{j}\right) \frac{\partial H}{\partial x_{j}}\right) .
\end{aligned}
$$

In this equation, the right end of FW-H equation can also be deemed as sound source items, where the first item is a Lighthill sound source item, namely, a quadrupole sound source; the second item is a sound source caused by surface fluctuation pressure (force distribution), namely, a dipole

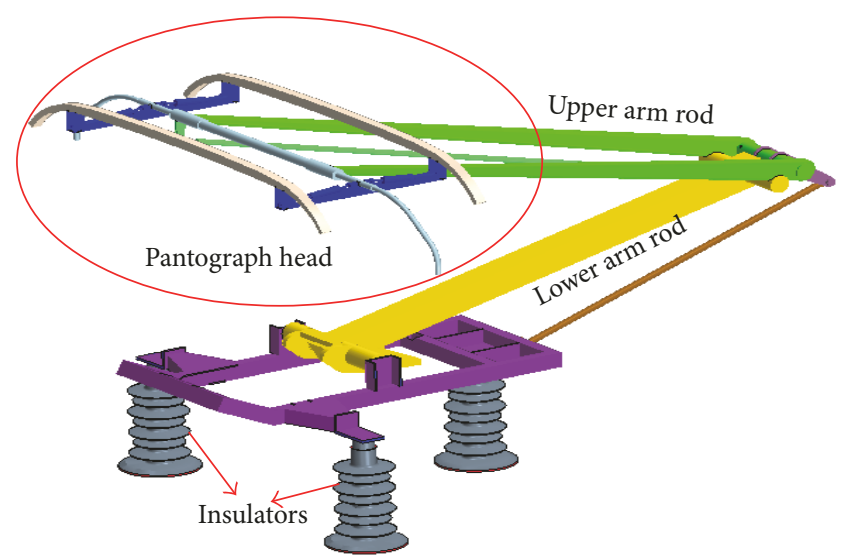

FIGURE 1: Geometric model of pantographs in high-speed trains.

sound source; the third item is a sound source caused by surface acceleration (fluid displacement distribution), namely, a monopole sound source. The Lighthill sound source item only exists outside the surface of a movable solid, while it is equal to zero inside the surface; the second and third sound source items are only formed on the solid surface.

\section{Computational Model of Pantographs and Experimental Verification}

Figure 1 presents a pantograph in high-speed trains adopted in this paper. A pantograph of high-speed trains is generally composed of a pantograph head, a frame, a bottom frame, and a transmission mechanism. A frame is composed of components such as a sway rod, an upper arm rod, a lower arm rod, a supporting rod, and a balance rod. All the components are connected by hinges. The frame is supported by the bottom frame. The bottom frame is fixed on the train top by insulators. The pantograph head is supported by the frame with a lifting device. The transmission mechanism acts on the lower arm rod to realize lifting actions. An aerodynamic lifting device is installed on the base and acts on a sector plate which is located on the lower part of the lower arm rod by a steel wire rope, so that pantograph lifting is achieved. Lower arm rod, upper frame, and pantograph head are made of stainless steel. The carbon slide plate is installed on the pantograph head support. The pantograph head support is suspended under 4 pull springs. Two torsional springs are installed between the pantograph head and upper frame.

The computational domain is shown in Figure 2. Length, width, and height of the computational domain are $40 \mathrm{~m}$, $20 \mathrm{~m}$, and $12 \mathrm{~m}$, respectively. The distance between insulator and ground is $0.15 \mathrm{~m}$. The cross section in the incoming flow direction of pantographs is the velocity inlet boundary and the size is equal to the running speed; the cross section right behind is a pressure exit boundary with the size of $0 \mathrm{~Pa}$; cross sections on the left and right sides and cross section right above are set as symmetric boundaries; surface of the pantograph is set as a wall boundary of non-slip wall face. 


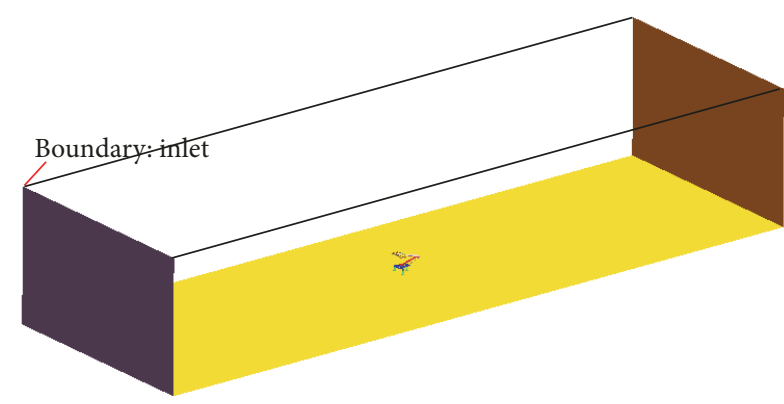

FIGURE 2: The computational domain of pantographs in high-speed trains.

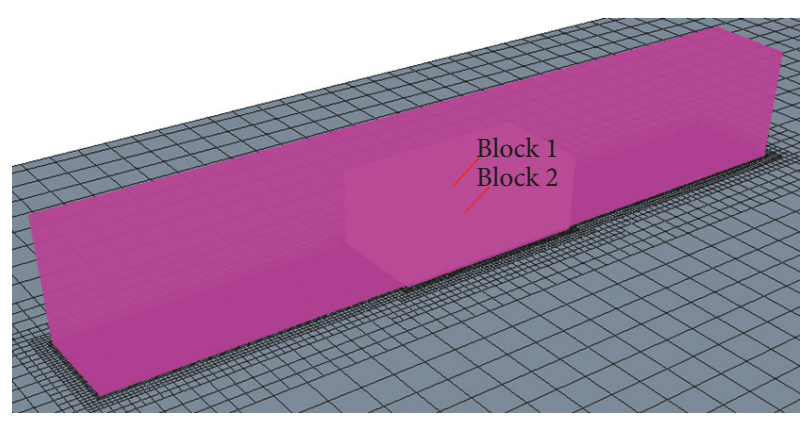

FIGURE 3: Refined meshes in the computational domain of pantographs.

In order to simulate ground effects, ground is set as a slip ground. Its slip speed is the running speed of pantographs.

Trimmer meshes are used to divide meshes of the computational domain of pantographs. Boundary layer meshes are divided on the surface of pantographs. Meanwhile, refined mesh regions are set around the pantograph. The maximum mesh size on the surface of pantographs is $15 \mathrm{~mm}$. Maximum size of space meshes is $500 \mathrm{~mm}$. In order to control the mesh quality of around the pantograph, refined regions around the pantograph are divided into 2 blocks. The maximum mesh size of small block is $15 \mathrm{~mm}$, and the maximum mesh size of big block is $30 \mathrm{~mm}$, as shown in Figure 3. During the computation, mesh self-adaptation technology is used for continuous adjustment of mesh density; local encryption is conducted, so that the computational accuracy can be ensured. To more accurately consider impacts of the pantograph surface on fluid flow, boundary layer mesh division is conducted on the surface, and 15-layer triangular prism meshes with growth rate of 1.1 and total thickness of $3 \mathrm{~mm}$ are set. Figure 4 shows surface meshes and boundary layer meshes of pantographs. Amount of meshes in the complete computation domain is about 42.15 million.

In order to speed up the convergence, three-dimensional incompressible viscidity steady computation is conducted firstly. Then, steady results are taken as the initial value of transient computation in the transient flow field. Sound source information is extracted till the physical field becomes steady, and the extracted sound source information is stored in a neutral document. Finally, sound source information in the neutral document is read. FW-H equation is used to solve noise values of observed points in the acoustic field.

RNG $k-\varepsilon$ turbulence model is used in the steady computation. SIMPLE algorithm is used in coupling between pressures and velocities [25-28]. Standard wall face function is used for the near wall face. Standard format discretization is applied to continuous equations. Second-order upwind format is applied to momentum equations, energy equations, and turbulence dissipation rate equations.

LES turbulence model is used for the transient computation. Smagorinsky-Lilly subgrid model based on hybrid length theory is used for simulating small-scale eddies. Second-order implicit expression is used as the time difference scheme. PISO algorithm is used for coupling between pressures and velocities. PRESTO format is used for separating continuous equations. Bounded Central Differencing is used to separate the momentum equation.

In addition, time step length $\Delta t$, transient time, and sound field computation time should be taken into account during the computation. Selection of computational time of transient sound field mainly depends on the concerned frequency component and computational convergence. In the paper, the maximum frequency of aerodynamic noises is set to be $5000 \mathrm{~Hz}$ and time $0.5 \mathrm{~s}$ is adopted. Therefore, the frequency resolution of aerodynamic noises of pantographs is $\Delta f=$ $2 \mathrm{~Hz}$.

The computation model of flow field for pantographs is very complicated, so its reliability should be verified by experimental test. The pantograph studied in the paper is a standard structure, and relevant aerodynamic characteristics are tested by a lot of published papers. Li et al. [29] used a wind tunnel to test aerodynamic forces of the pantograph. Main structures of the pantograph in this paper are basically consistent with the experimental model. Therefore, experimental results in the proposed reference can be used to verify the numerical model in this paper. According to experimental test, this paper conducted a numerical computation for aerodynamic resistance of pantographs within $210-370 \mathrm{~km} / \mathrm{h}$ with the step length of $10 \mathrm{~km} / \mathrm{h}$. Computational results are compared with experimental results, as shown in Figure 5. It is shown in Figure 5 that change trends between numerical simulation and experimental test are very consistent; the relative error between the experimental test and numerical simulation is computed, and the maximum relative error is $4.8 \%$. The result fully proves that the numerical model in this paper is reliable. Numerical results under each speed are smaller than experimental results. The reason may be that the numerical simulation is an ideal state which only considered incoming flow speed, while experimental test will be affected by the tested environments and installation of specimens and aerodynamic resistance will be increased.

\section{Characteristics of Flow Field for Pantographs}

The experimental test proves the reliability of the numerical model of pantographs. Therefore, the model can be used to study the subsequent contents. Contours of surface pressures of pantographs with running speed of $350 \mathrm{~km} / \mathrm{h}$ are extracted, 

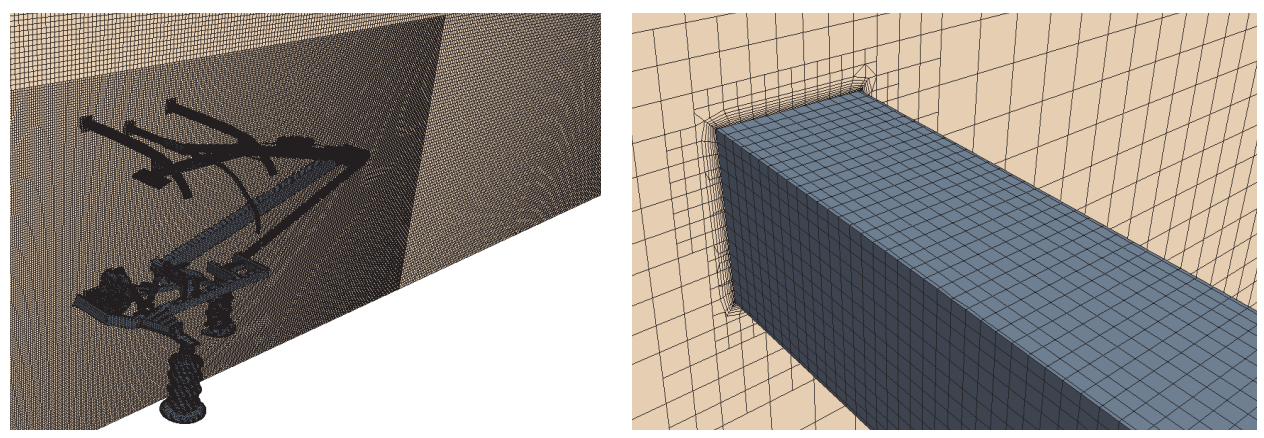

FIGURE 4: Surface meshes and boundary layer meshes of pantographs.

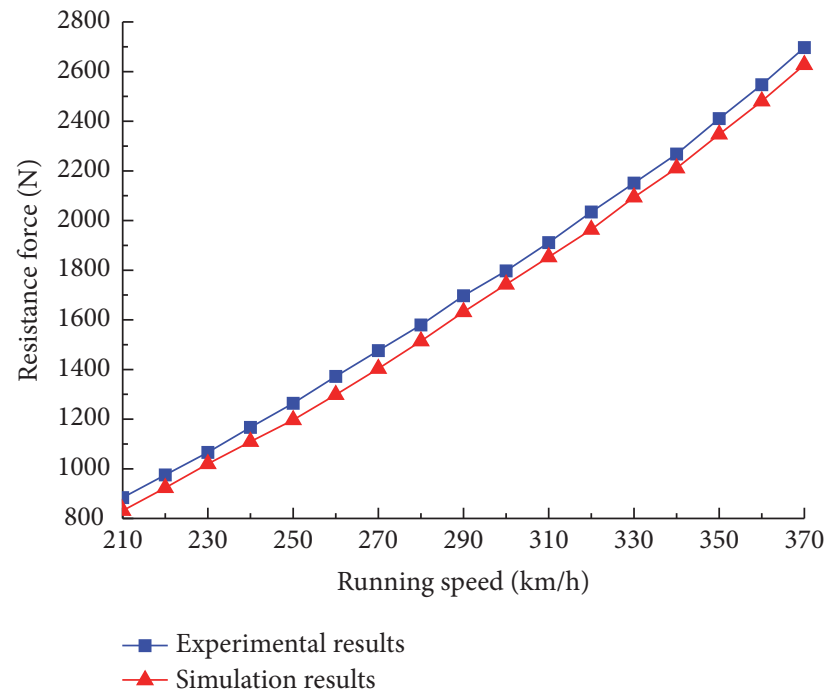

FIGURE 5: Experimental test and comparison of aerodynamic resistance for pantographs.

as shown in Figure 6. Obviously, most surfaces on the windward side are located at positions with large positive pressures, mainly including pantograph heads, sector plates, bottom frames, and insulators. Pressure distributions on the pantograph surface are symmetric mainly because the pantograph structure is symmetric and impacts of train bodies on the pantograph are not considered in this computation. Maximum positive pressure is located at pantograph heads, base plates, and insulators of the windward side, with the size of $5289 \mathrm{~Pa}$. The maximum negative pressure is located on the leeward side of insulators, with size of $24052 \mathrm{~Pa}$. Surface pressures of pantographs present very strong symmetry along the longitudinal center plane.

Figure 7 shows the velocity distribution on the longitudinal center plane of pantographs which run at the speed of $350 \mathrm{~km} / \mathrm{h}$. It is shown in Figure 7 that pantographs with large velocity changes are located at pantograph heads, bottom frames, and hinge positions. Along the vertical direction of pantographs, the velocity distribution is symmetric, and the maximum velocity is distributed at the slide plate of pantographs with the size of $110 \mathrm{~m} / \mathrm{s}$; the minimum flow velocity is located at the hinge part between bottom frames

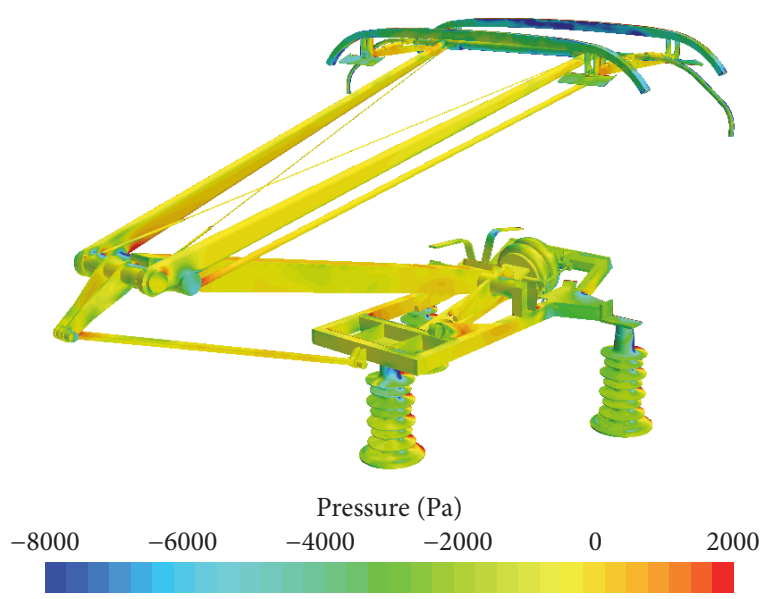

FIgURE 6: Contours of surface pressures.

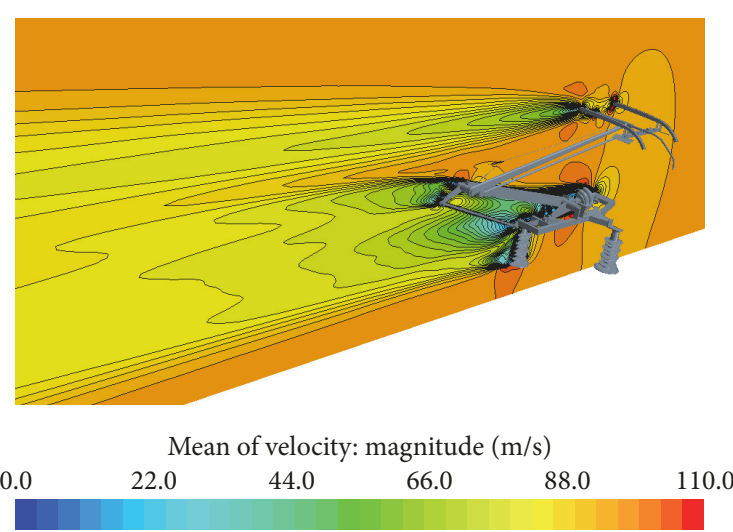

FIGURE 7: Velocity distributions at center cross section.

and pull rods, with the size of $0 \mathrm{~m} / \mathrm{s}$. It is found that velocity distributions and pressure distributions of the pantograph have similar rules. Contours of velocities in the pantograph region are also symmetric.

Figure 8 shows the distribution contours of eddies on the longitudinal center plane for pantographs which run at speed of $350 \mathrm{~km} / \mathrm{h}$. It is shown in Figure 8 that, during the high-speed running of pantographs, due to disturbance of pantograph heads, bottom frames, and insulators, airflows 


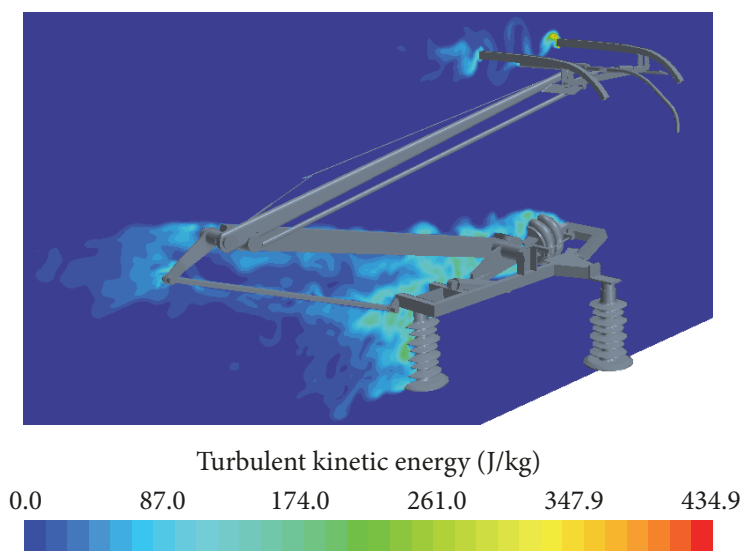

FIGURE 8: Eddy distributions on center cross section of pantographs.

have Karman vortex street phenomenon at the carbon slide plate of pantograph heads, and cylindrical turbulent flow phenomenon does not take place in the bottom frame. Obviously, single-frequency noises will be generated during the high-speed running of pantographs. Eddies with different rotation directions and scales are in these regions such as pantograph heads, hinged joints, bottom frames, and insulators. Big eddies are at pantograph heads and bottom frames. In addition, eddies are continuously shed and reconstructed at the rear part of pantographs, and big eddies are broken continuously and small eddies are formed. Fluctuation pressures of pantographs are finally affected by these eddies, and aerodynamic noise sources are formed.

Figure 9 presents distribution contours of velocity isosurface based on Q-criterion, concerning the pantograph which runs at speed of $350 \mathrm{~km} / \mathrm{h}$, where values are $500 / \mathrm{s}^{2}$, $1000 / \mathrm{s}^{2}, 2000 / \mathrm{s}^{2}, 5000 / \mathrm{s}^{2}, 10000 / \mathrm{s}^{2}$, and $20000 / \mathrm{s}^{2}$. It is shown in Figure 9 that when the high-speed train is running, through disturbance of pantograph heads, bottom frames, and insulators, airflows form a series of eddies on the rear part. Impacted by airflows, these eddies move towards the rear side of train and are shed and reconstructed continuously. Eddies are generated on the front pantograph head and impacted the rear pantograph head, and big turbulence energy is generated on the pantograph head. Therefore, the nonsteady aerodynamic force is very obvious. Similarly, big eddies are in these regions between the bottom frame and lower arm rods. Eddies are distributed obviously at the geometric center of pantographs. Eddies on pantograph heads and bottom frames generated a series of tail flows behind pantographs with time and space. The tail flow also generated big fluctuation pressures, which will further cause a strong noise radiation.

\section{Characteristics of Aerodynamic Noises}

5.1. Aerodynamic Noise Sources. Broadband Noise Sources Model in the software STAR-CCM+ is used to compute the distribution of noise sources on the surface of pantographs. Therefore, useful noise source information can be obtained and help to judge the parts which mainly generated noises.
However, it cannot be used to predict the radiation of visible noises. Noise source distribution on the pantograph surface can be denoted by dipole noise sources, and the environment noise can be denoted by quadrupole noise sources.

Figure 10 presents distribution contours of sound power levels on the surface of pantographs which run on the flat ground at speed of $350 \mathrm{~km} / \mathrm{h}$ (dipole noise sources). Figure 11 presents distribution contours of sound power levels on different longitudinal cross sections of pantographs which run on the flat ground at speed of $350 \mathrm{~km} / \mathrm{h}$ (quadrupole noise sources). It is shown in Figure 10 that peaks of sound power levels of slide plates, pantograph heads, balance rods, insulators, bottom frames, and push rods reach $120 \mathrm{~dB}$, while sound power levels of other parts are small. On the pantograph surface with big sound power, the fluctuation pressure is also big, and strong aerodynamic noises are caused. Sound powers of slide plates, pantograph heads, balance rods, and insulators on the windward side are $118 \mathrm{~dB}, 119 \mathrm{~dB}, 105 \mathrm{~dB}$, and $100 \mathrm{~dB}$, respectively. As shown in Figure 11, quadrupole noise distributions on longitudinal symmetric planes of pantographs prove that main noise sources in the pantograph region are pantograph heads, hinge joints, bottom frames, and insulators on the windward side; serious aerodynamic noises are in tail regions such as pantograph heads, bottom frames, hinge joints, and insulators; quadrupole noises are distributed on the pantograph head and have cylindrical flow turbulence phenomenon. The results show that quadrupole noises are related to characteristics of flow fields around the pantograph, as shown in Figures 7 and 8.

5.2. Aerodynamic Noises in the Far-Field. In order to study distribution characteristics of aerodynamic noises of pantographs in the far-field, 5 observed points are placed around the geometric center of pantographs along the horizontal direction. Two observed points satisfied duplation relations, where coordinates are as follows: $r 1(0 \mathrm{~m}, 1.875 \mathrm{~m}$, $3 \mathrm{~m}), r 2(0 \mathrm{~m}, 3.75 \mathrm{~m}, 3 \mathrm{~m}), r 3(0 \mathrm{~m}, 7.5 \mathrm{~m}, 3 \mathrm{~m}), r 4(0 \mathrm{~m}$, $15 \mathrm{~m}, 3 \mathrm{~m}), r 5(0 \mathrm{~m}, 30 \mathrm{~m}, 3 \mathrm{~m})$. Relations between observed points and coordinate plane, which are computed according to the aerodynamic noise of pantographs in the far-field, are shown in Figure 12.

A-weighting is conducted on sound pressures of the aerodynamic noise at observed points. Hann window is selected for processing data. Overlap Factor is 0.5 . Start point of data recording is $0.25 \mathrm{~s}$. End point of data recording is $0.7 \mathrm{~s}$. Therefore, based on the processed data, the highest frequency is $5000 \mathrm{~Hz}$, and the frequency resolution is $2 \mathrm{~Hz}$. Figure 13 presents noise spectrums of observed points $r 1, r 2, r 3, r 4$, and $r 5$. It is shown in Figure 13:

(1) Due to the structural specificity, the pantograph is consisted of a lot of cylindrical rods. The radiated noises of these cylindrical rods have an obvious single-frequency characteristic. These single-frequency characteristics will cause obvious peak noises. As a result, aerodynamic noises of the pantograph have single-frequency and peak noises, where main frequencies are $293 \mathrm{~Hz}, 586 \mathrm{~Hz}, 880 \mathrm{~Hz}$, and $1173 \mathrm{~Hz}$. At observed points $r 1, r 2$, and $r 3$, the third-order main frequency $880 \mathrm{~Hz}$ has the largest amplitude. At observed 


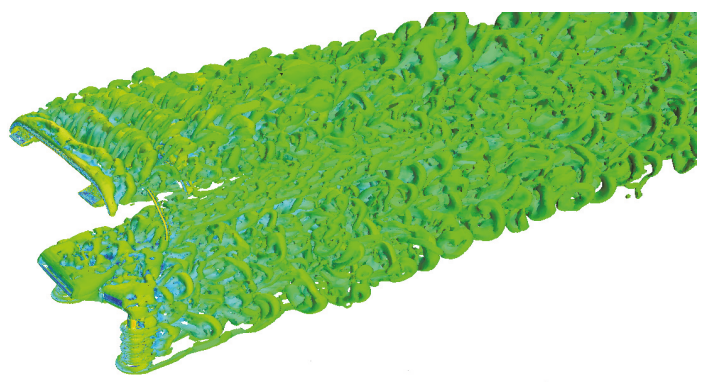

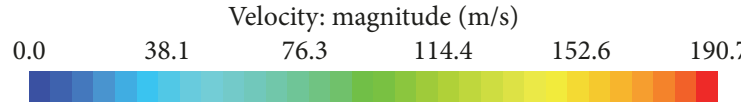

(a) Velocity isosurface $=500 / \mathrm{s}^{2}$
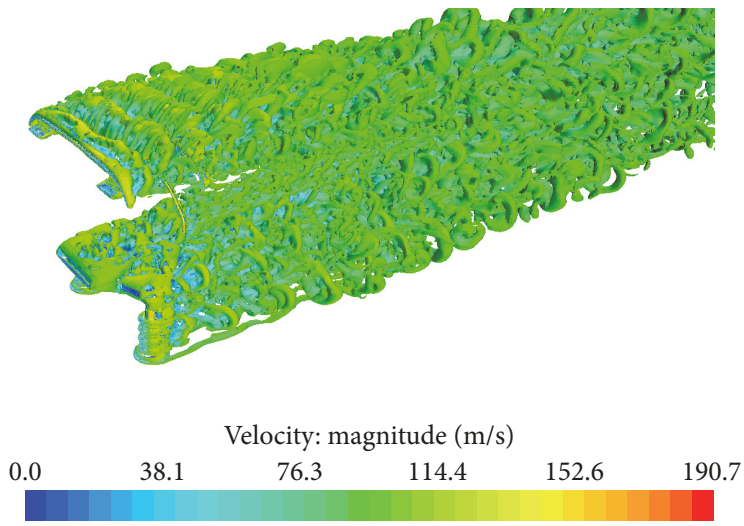

(c) Velocity isosurface $=2000 / \mathrm{s}^{2}$
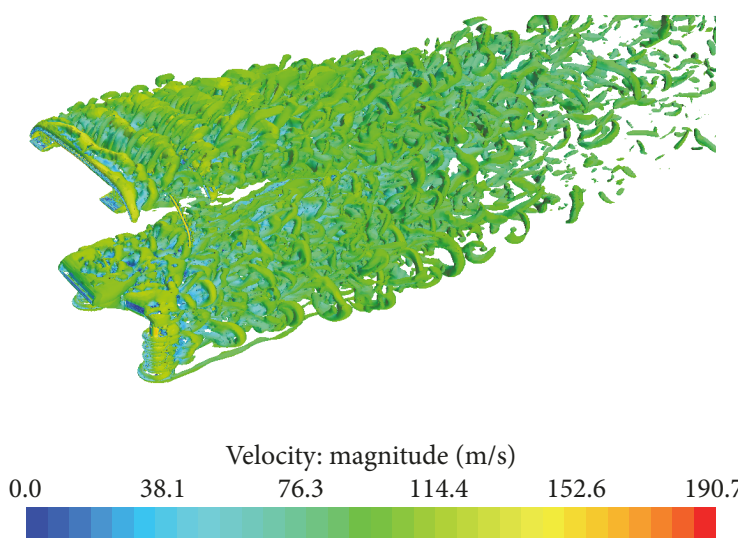

(e) Velocity isosurface $=10000 / \mathrm{s}^{2}$

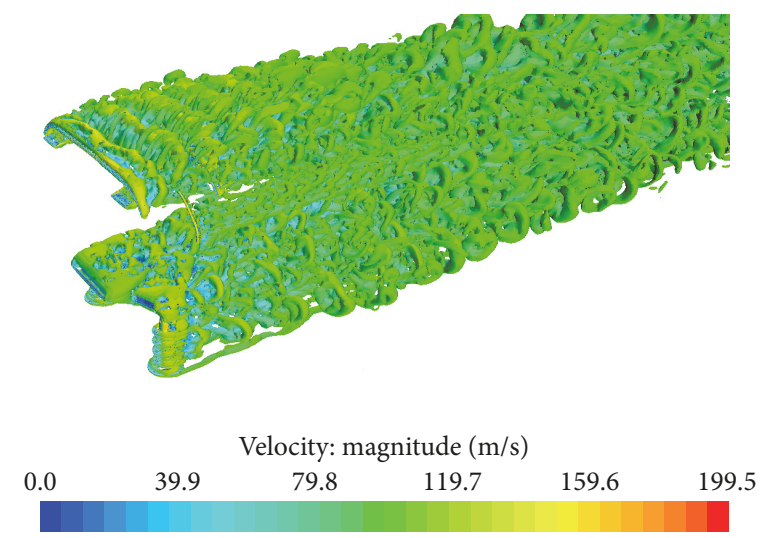

(b) Velocity isosurface $=1000 / \mathrm{s}^{2}$
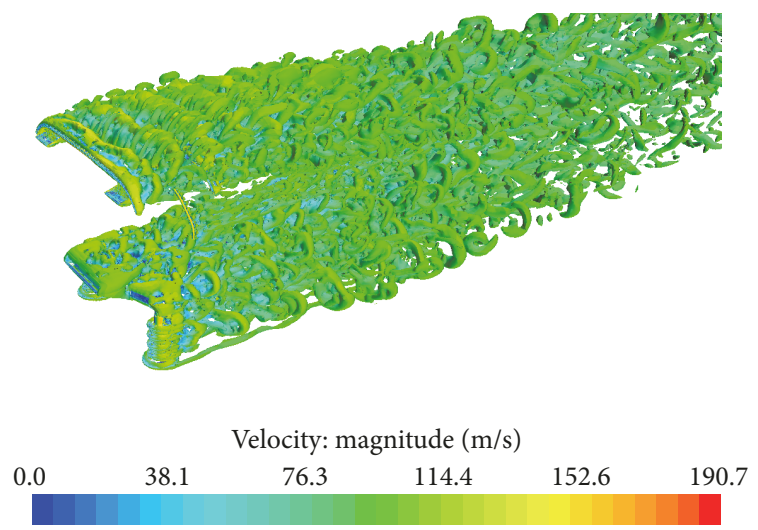

(d) Velocity isosurface $=5000 / \mathrm{s}^{2}$
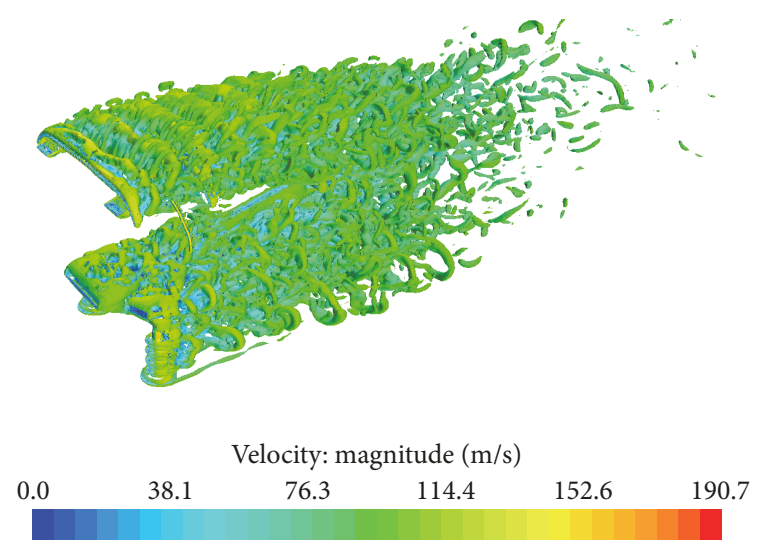

(f) Velocity isosurface $=20000 / \mathrm{s}^{2}$

FIGURE 9: Distribution contours of velocity isosurface based on Q-criterion for pantographs.

points $r 4$ and $r 5$, the first-order main frequency $293 \mathrm{~Hz}$ has the largest amplitude.

(2) At the observed point $r 1$, frequency spectrum amplitudes corresponding to main frequencies $293 \mathrm{~Hz}, 586 \mathrm{~Hz}$, $880 \mathrm{~Hz}$, and $1173 \mathrm{~Hz}$ are $99.3 \mathrm{~dB}, 102.5 \mathrm{~dB}, 88.9 \mathrm{~dB}$, and $80.8 \mathrm{~dB}$. At the observed point $r 2$, frequency spectrum amplitudes corresponding to main frequencies $293 \mathrm{~Hz}, 586 \mathrm{~Hz}$, $880 \mathrm{~Hz}$, and $1173 \mathrm{~Hz}$ are $88.5 \mathrm{~dB}, 91.4 \mathrm{~dB}, 81.9 \mathrm{~dB}$, and $73.8 \mathrm{~dB}$. At observed point $r 3$, frequency spectrum amplitudes corresponding to main frequencies $293 \mathrm{~Hz}, 586 \mathrm{~Hz}, 880 \mathrm{~Hz}$, and
$1173 \mathrm{~Hz}$ are $80.6 \mathrm{~dB}, 81.2 \mathrm{~dB}, 71.3 \mathrm{~dB}$, and $65.4 \mathrm{~dB}$. At the observed point $r 4$, frequency spectrum amplitudes corresponding to main frequencies $293 \mathrm{~Hz}, 586 \mathrm{~Hz}, 880 \mathrm{~Hz}$, and $1173 \mathrm{~Hz}$ are $74.9 \mathrm{~dB}, 70.4 \mathrm{~dB}, 64.7 \mathrm{~dB}$, and $59.9 \mathrm{~dB}$. At the observed point $r 5$, frequency spectrum amplitudes corresponding to main frequencies $293 \mathrm{~Hz}, 586 \mathrm{~Hz}, 880 \mathrm{~Hz}$, and $1173 \mathrm{~Hz}$ are $68.7 \mathrm{~dB}, 62.1 \mathrm{~dB}, 57.6 \mathrm{~dB}$, and $53.5 \mathrm{~dB}$.

(3) At the first-order main frequency $293 \mathrm{~Hz}$, sound pressure attenuation amplitudes from observed point $r 1$ to observed point $r 5$ are $10.8 \mathrm{~dB}, 7.9 \mathrm{~dB}, 5.7 \mathrm{~dB}$, and $6.2 \mathrm{~dB}$; at 


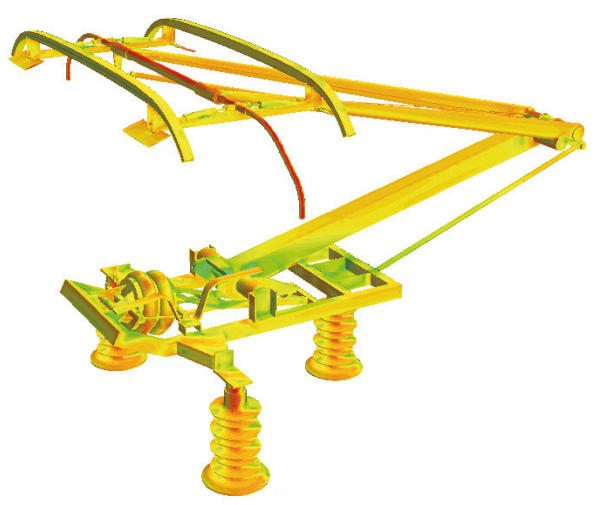

Curle surface acoustic power $(\mathrm{dB})$

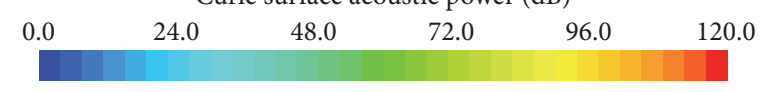

FiguRE 10: Distribution of dipole noise sources.

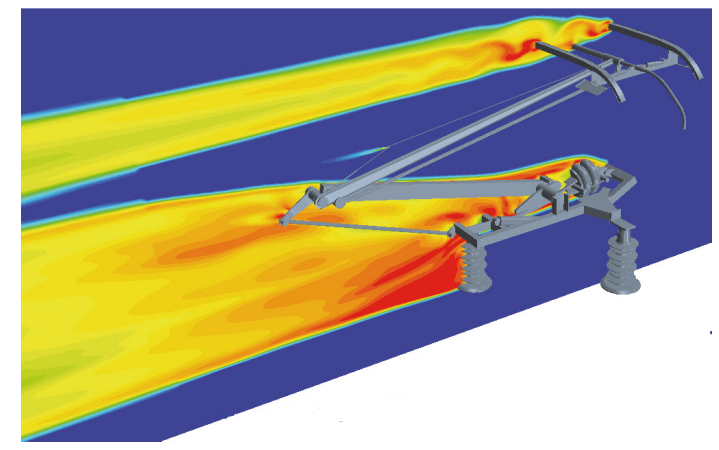

Proudman acoustic power $(\mathrm{dB})$

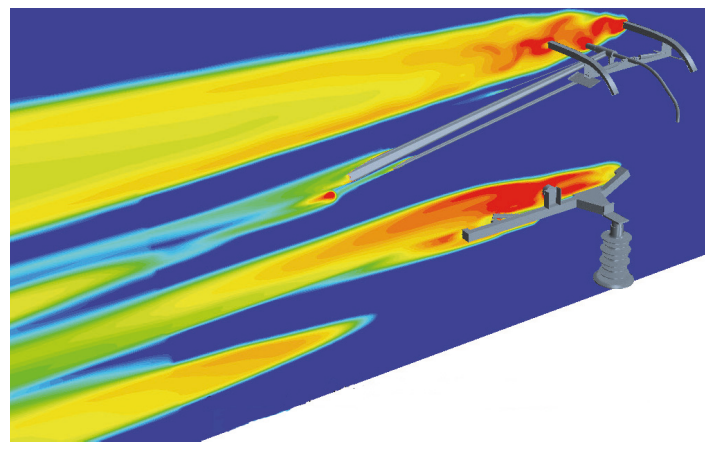

Proudman acoustic power $(\mathrm{dB})$

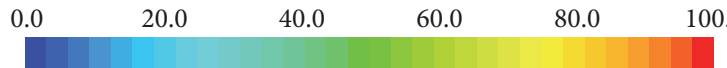

(a) The longitudinal center symmetric plane (b) Location $0.2 \mathrm{~m}$ away from the longitudinal center plane
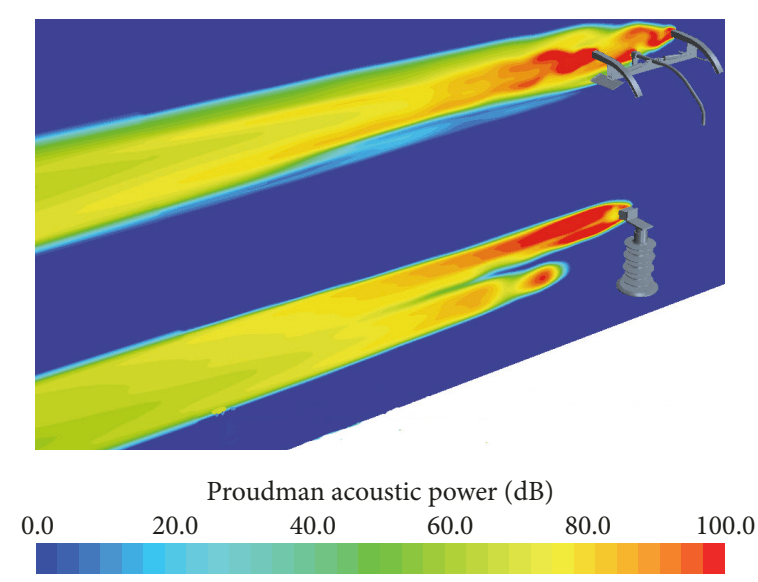

(c) Location $0.4 \mathrm{~m}$ away from the longitudinal center plane

FIGURE 11: Distribution of quadrupole noise sources for pantographs. 


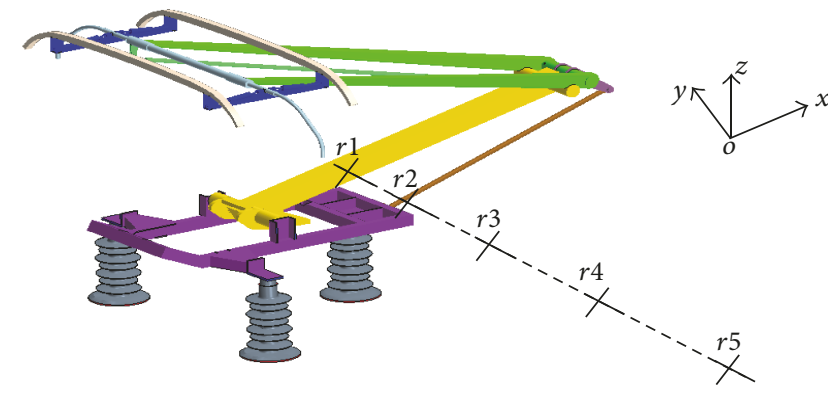

FIGURE 12: Distribution of observed points of aerodynamic noises in the far-field.

the second-order main frequency $586 \mathrm{~Hz}$, sound pressure attenuation amplitudes from observed point $r 1$ to observed point $r 5$ are $11.1 \mathrm{~dB}, 10.2 \mathrm{~dB}, 10.8 \mathrm{~dB}$, and $8.3 \mathrm{~dB}$; at the thirdorder main frequency $880 \mathrm{~Hz}$, sound pressure attenuation amplitudes from observed point $r 1$ to observed point $r 5$ are $7.0 \mathrm{~dB}, 10.6 \mathrm{~dB}, 6.6 \mathrm{~dB}$, and $7.1 \mathrm{~dB}$; at the fourth-order main frequency $1173 \mathrm{~Hz}$, sound pressure attenuation amplitudes from observed point $r 1$ to observed point $r 5$ are $6.9 \mathrm{~dB}$, $8.4 \mathrm{~dB}, 5.5 \mathrm{~dB}$, and $6.4 \mathrm{~dB}$. Obviously, the farther the position is from the noise source, the faster the sound pressure attenuation will be. When the distance of two observed points is increased by double, the attenuation amplitude of sound pressure levels is about $6.6 \mathrm{~dB}$. It is thus clear that attenuation characteristics of aerodynamic noises for pantographs are similar to cylindrical turbulences, which can be seem to be a typical point sound source.

5.3. Radiating Characteristics of Aerodynamic Noises. The analyzed results prove that pantographs are a main aerodynamic noise source of high-speed trains. Therefore, this part mainly studies radiating characteristics of aerodynamic noises for pantographs which run at speed of $350 \mathrm{~km} / \mathrm{h}$. Time-domain signals of fluctuation pressures of pantographs are extracted in the flow field. The boundary element method is used to solve sound pressures on receiving points because it can compute the acoustic results more quickly. According to the rule of the boundary element mesh, one wave length should include six elements. The computational frequency is $5000 \mathrm{~Hz}$, and the element size should be less than $11 \mathrm{~mm}$. In this paper, the maximum element size is $10 \mathrm{~mm}$. Therefore, there are 5021 elements and 5832 nodes. Acoustic software VIRTUAL.LAB is used to compute acoustic propagation on the pantograph surface [30-33]. Based on sound pressure boundary conditions, fluctuation pressures on the pantograph surface, which are obtained using CFD, are mapped into the acoustic meshes. DFT is used for data transfer of fluctuation pressures. Finally, the acoustic meshes can obtain all the flow field results, acoustic response computation is then conducted. Through analyzing far-field responses, radiating characteristics of aerodynamic noises for pantographs in the far-field are obtained. Figure 14 presents acoustic meshes of pantographs, where the maximum mesh size satisfied requirements for maximum frequency. Figure 15 presents comparison contours of radiating characteristics of aerodynamic noise at $293 \mathrm{~Hz}, 586 \mathrm{~Hz}, 880 \mathrm{~Hz}$, and $1173 \mathrm{~Hz}$, which are obtained through the computation.

Results in Figure 15 prove that aerodynamic noises of the pantograph are mainly distributed in mid-frequency and high-frequency bands, and aerodynamic noise energies in low-frequency bands are lower than that in mid-frequency and high-frequency bands. When the pantograph runs at speed of $350 \mathrm{~km} / \mathrm{h}$, the main radiation directions of aerodynamic noises at $293 \mathrm{~Hz}$ are the upper left direction and upper right direction; main radiation directions of aerodynamic noises at $586 \mathrm{~Hz}$ and $880 \mathrm{~Hz}$ are the right above direction, while the left direction and the right direction are not the main directions of aerodynamic noises; main radiation directions of aerodynamic noises at $1173 \mathrm{~Hz}$ are the upper left direction and upper right direction, where main energies at the position are stronger than that in low frequencies and mainly the pantograph head makes contributions to radiation energies of aerodynamic noises in the far-field. Therefore, it is clear that, in high frequencies, mainly the pantograph head makes contributions to aerodynamic noises of pantographs in the far-field. Obviously, noise reduction effects will be the most obvious if the optimization design can be conducted on the pantograph head.

\section{Conclusions}

(1) When the high-speed train is running, through disturbance of pantograph heads, bottom frames, and insulators, airflows have Karman vortex street phenomenon at the carbon slide plate which is located at the pantograph head, and cylindrical turbulence phenomenon does not take place in the bottom frame region. Obviously, single-frequency noises will be caused during the high-speed running of pantographs. Eddies with different rotation directions and scales are in these regions such as pantograph heads, hinge joints, bottom frames, and insulators, while big eddies are at pantograph heads and bottom frames. Finally, these eddies will affect fluctuation pressures of pantographs and form aerodynamic noise sources.

(2) Slide plates, pantograph heads, balance rods, insulators, bottom frames, and push rods are the main aerodynamic noise source of pantographs. Pantograph heads, hinge joints, bottom frames, and insulators are main radiating parts of aerodynamic noises of pantographs.

(3) The propagation of aerodynamic noises for pantographs is characterized in that main radiation energies of pantographs are in mid-frequency and high-frequency bands, and main radiation directions are the upper left direction and upper right direction of pantograph heads. In high-frequency bands, mainly the pantograph head make contributions to aerodynamic noises of pantographs in the far-field. Obviously, noise reduction effects will be the most obvious if the optimization design can be conducted on the pantograph head.

(4) Aerodynamic noises of pantographs have singlefrequency components in the far-field, where main frequencies are $293 \mathrm{~Hz}, 586 \mathrm{~Hz}, 880 \mathrm{~Hz}$, and $1173 \mathrm{~Hz}$. At observed points $r 1, r 2$, and $r 3$, the third-order main frequency $880 \mathrm{~Hz}$ has the largest amplitude. At observed points $r 4$ 


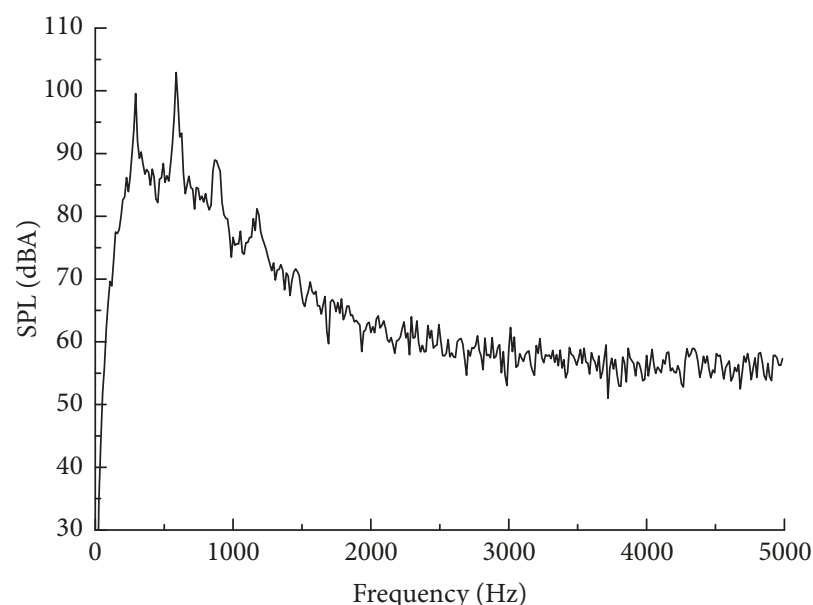

(a) Observed point $r 1$

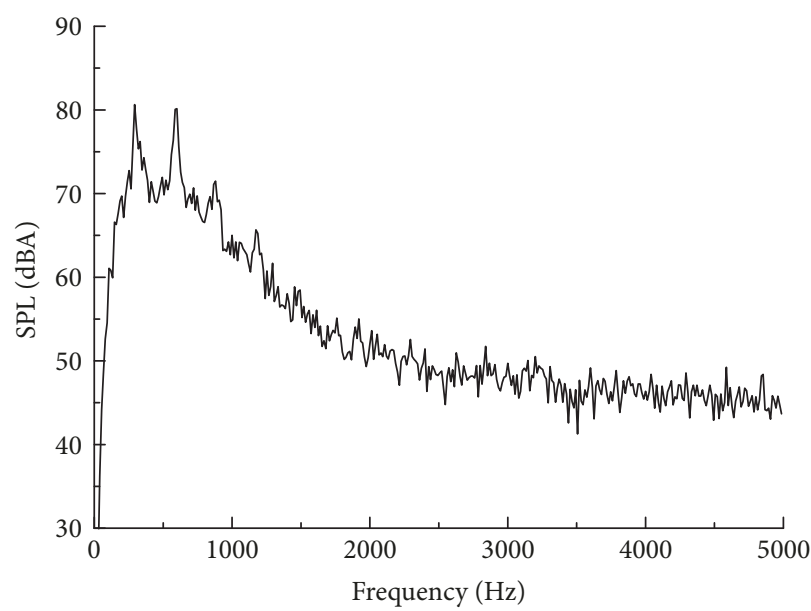

(c) Observed point $r 3$

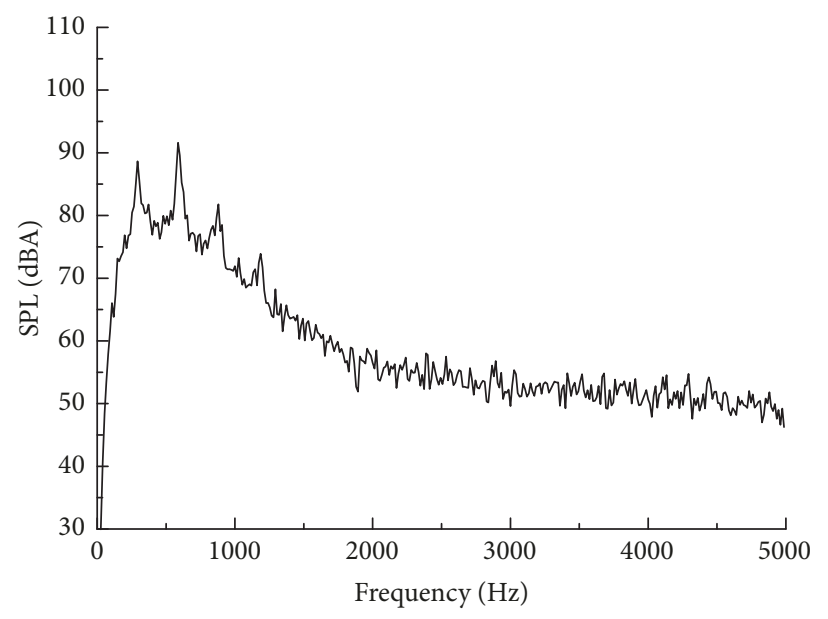

(b) Observed point $r 2$

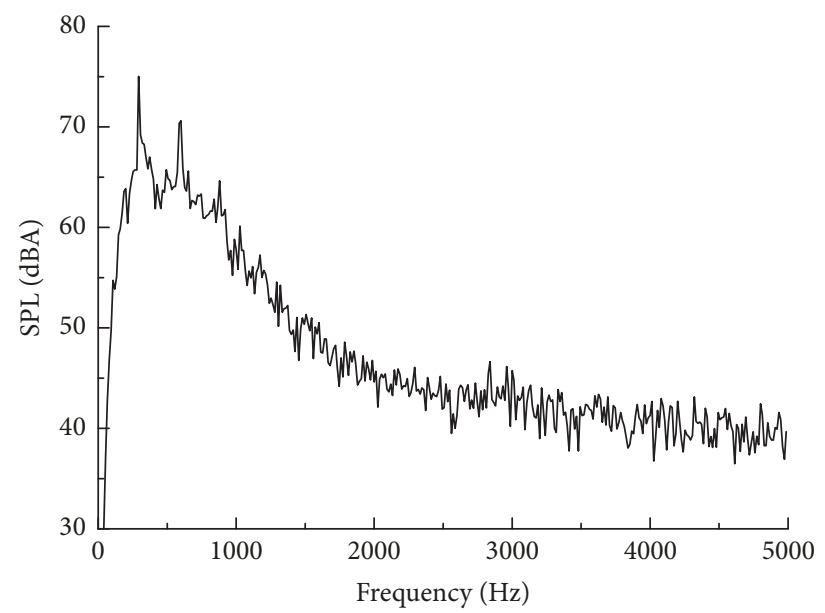

(d) Observed point $r 4$

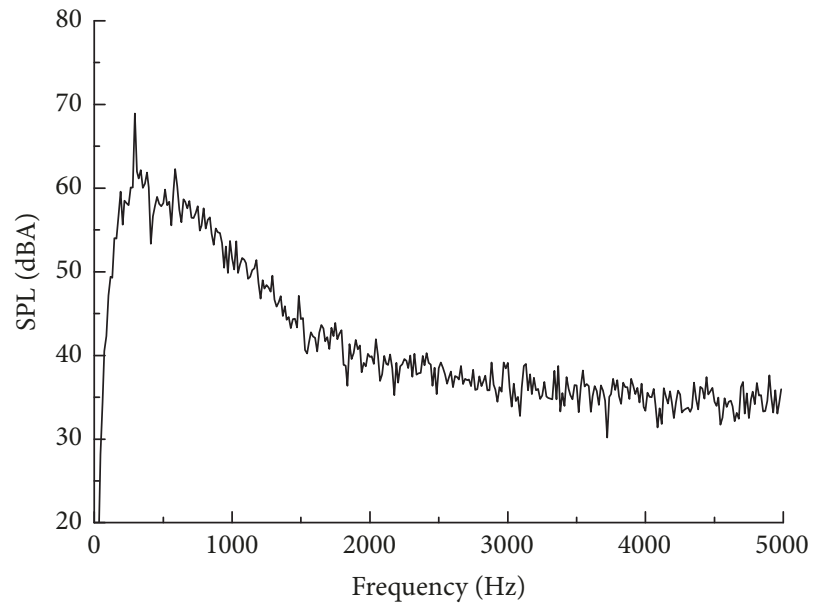

(e) Observed point $r 5$

FIGURE 13: Comparisons of frequency spectrums at observed points.

and $r 5$, the first-order main frequency $293 \mathrm{~Hz}$ has the largest amplitude. When the distance of two observed points is increased by double, the attenuation amplitude of sound pressure levels is about $6.6 \mathrm{~dB}$. It is clear that attenuation characteristics of aerodynamic noises for pantographs are similar to cylindrical turbulences in the farfield, which can be seem to be a typical point sound source. 


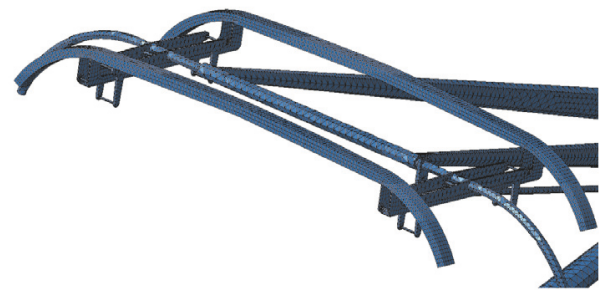

FIGURE 14: Acoustic meshes of pantographs in high-speed trains.

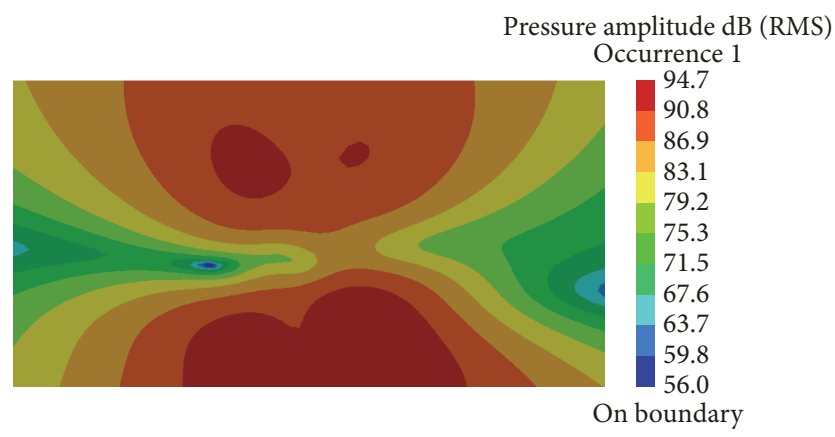

(a) The first main frequency $=293 \mathrm{~Hz}$

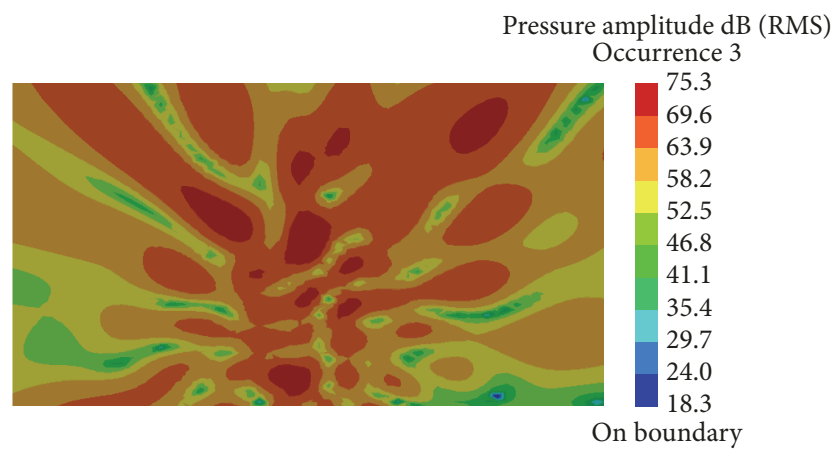

(c) The third main frequency $=880 \mathrm{~Hz}$

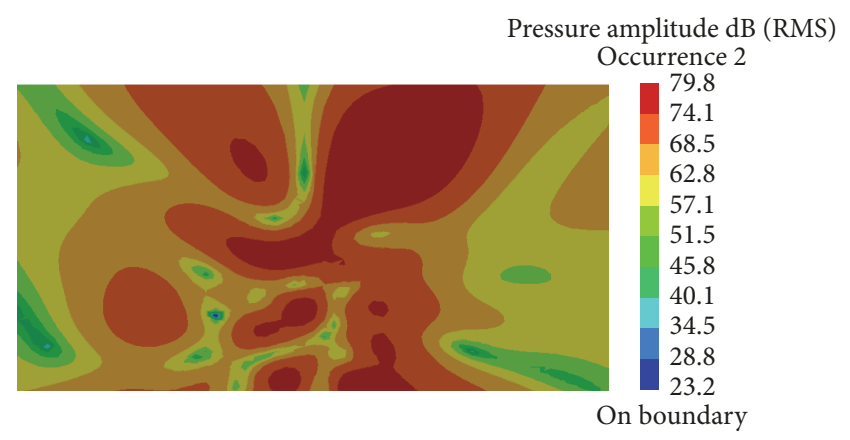

(b) The second main frequency $=586 \mathrm{~Hz}$

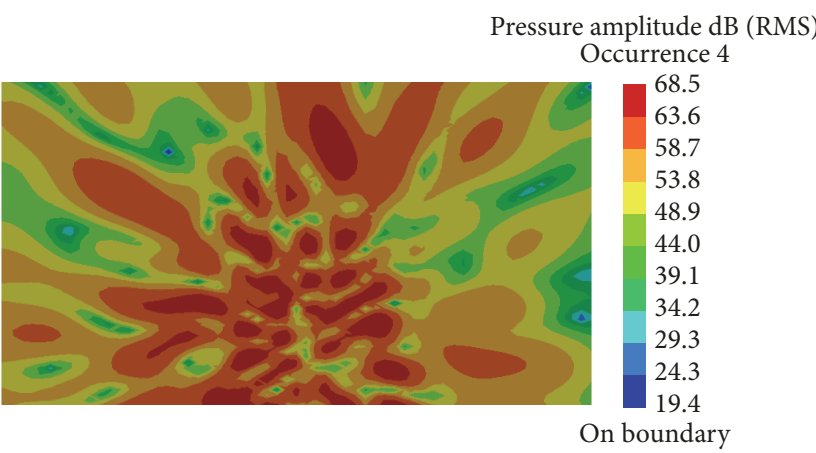

(d) The fourth main frequency $=1173 \mathrm{~Hz}$

FIGURE 15: Aerodynamic noise radiation of pantographs in high-speed trains.

\section{Conflicts of Interest}

The authors declare that there are not any conflicts of interest regarding the publication of this paper.

\section{Acknowledgments}

This work was supported by NSFC Projects of International Cooperation and Exchanges (Grant no. 71611530712) and by Fundamental Research Funds for the Central Universities of China (Grant no. 201713051).

\section{References}

[1] C. Mellet, F. Létourneaux, F. Poisson, and C. Talotte, "High speed train noise emission: latest investigation of the aerodynamic/rolling noise contribution," Journal of Sound and Vibration, vol. 293, no. 3-5, pp. 535-546, 2006.
[2] E. Latorre Iglesias, D. J. Thompson, M. Smith, T. Kitagawa, and N. Yamazaki, "Anechoic wind tunnel tests on high-speed train bogie aerodynamic noise," International Journal of Rail Transportation, vol. 5, no. 2, pp. 87-109, 2017.

[3] E. Latorre Iglesias, D. J. Thompson, and M. G. Smith, "Component-based model to predict aerodynamic noise from high-speed train pantographs," Journal of Sound and Vibration, vol. 394, pp. 280-305, 2017.

[4] Y. Zhang, J. Zhang, T. Li, and L. Zhang, "Investigation of the aeroacoustic behavior and aerodynamic noise of a high-speed train pantograph," Science China Technological Sciences, vol. 60, no. 4, pp. 561-575, 2017.

[5] Y. Mei, C. Zhang, C. Zhou, Y. Jia, and M. Wu, "Research on the aural discomfort when a single train passes through a super long tunnel," Jixie Gongcheng Xuebao/Journal of Mechanical Engineering, vol. 51, no. 14, pp. 100-107, 2015.

[6] G.-Q. Li, Z.-L. Wang, S. Chen, and Y.-L. Xu, "Field measurements and analyses of environmental vibrations induced by 
high-speed Maglev," Science of the Total Environment, vol. 568, pp. 1295-1307, 2016.

[7] C. Noger, J. C. Patrat, J. Peube, and J. L. Peube, "Aeroacoustical study of the TGV pantograph recess," Journal of Sound and Vibration, vol. 231, no. 3, pp. 563-575, 2000.

[8] T. Kitagawa and K. Nagakura, "Aerodynamic noise generated by Shinkansen cars," Journal of Sound and Vibration, vol. 231, no. 3, pp. 913-924, 2000.

[9] K. Nagakura, "Localization of aerodynamic noise sources of Shinkansen trains," Journal of Sound and Vibration, vol. 293, no. 3-5, pp. 547-556, 2006.

[10] Y. Gao, Y. G. Wang, and J. T. Wang, “Testing study of aerodynamic noise for high-speed train model in aero-acoustic wind tunnel," Tech. Rep., Technical Acoustic, 2013.

[11] W. F. King III, "A précis of developments in the aeroacoustics of fast trains," Journal of Sound and Vibration, vol. 193, no. 1, pp. 349-358, 1996.

[12] J.-L. Liu, J.-Y. Zhang, and W.-H. Zhang, "Study of computational method of far-field aerodynamic noise of a high-speed train considering ground effect," Jisuan Lixue Xuebao/Chinese Journal of Computational Mechanics, vol. 30, no. 1, pp. 94-100, 2013.

[13] J. Du, J. Liang, and A. Tian, "Analysis of aeroacoustics characteristics for pantograph of high-speed trains," Xinan Jiaotong Daxue Xuebao/Journal of Southwest Jiaotong University, vol. 50, no. 5, pp. 935-941, 2015.

[14] M. Ikeda, M. Suzuki, and K. Yoshida, "Study on optimization of panhead shape possessing low noise and stable aerodynamic characteristics," Quarterly Report of RTRI, vol. 47, no. 2, pp. 7277, 2006.

[15] Y. Xiao G and Y. Shi, "Aerodynamic noise calculation and shape optimization of high-speed train pantograph insulators," Journal of Railway Science and Engineering, vol. 9, no. 6, pp. 7276, 2012.

[16] H.-H. Yu, J.-C. Li, and H.-Q. Zhang, "On aerodynamic noises radiated by the pantograph system of high-speed trains," Acta Mechanica Sinica, vol. 29, no. 3, pp. 399-410, 2013.

[17] M. J. Lighthill, “On sound generated aerodynamically. I: general theory," Proceedings of the Royal Society A Mathematical, Physical and Engineering Sciences, vol. 211, pp. 564-587, 1952.

[18] J. E. F. Williams and D. L. Hawkings, "Sound generation by turbulence and surfaces in arbitrary motion," Philosophical Transactions of the Royal Society A: Mathematical, Physical \& Engineering Sciences, vol. 264, no. 1151, pp. 321-342, 1969.

[19] A. Neifeld, C. Appel, R. Ewert et al., "Aeroacoustics research in Europe: The CEAS-ASC report on 2013 highlights," Journal of Sound and Vibration, vol. 340, pp. 39-60, 2015.

[20] S. Redonnet, D. P. Lockard, M. . Khorrami, and M. M. Choudhari, "The non-reflective interface: an innovative forcing technique for computational acoustic hybrid methods," International Journal for Numerical Methods in Fluids, vol. 81, no. 1, pp. 22-44, 2016.

[21] K. Liu, S. Zhou, X. Li et al., "Flow-induced noise simulation using detached eddy simulation and the finite element acoustic analogy method," Advances in Mechanical Engineering, vol. 8, no. 7, pp. 1-8, 2016.

[22] S.-S. Li, M. Li, F. Yang, J.-F. Li, and K. Wang, "Aero acoustic noise analysis of a locomotive cooling system ducts and structure optimization," International Journal of Engineering and Technology Innovation, vol. 5, no. 3, pp. 178-188, 2015.
[23] M. Maizi, R. Dizene, and M. C. Mihoubi, "Reducing noise generated from a wind turbine blade by pitch angle control using CFD and acoustic analogy," Journal of Applied Fluid Mechanics, vol. 10, no. 4, pp. 1201-1209, 2017.

[24] M. Ghasemian and A. Nejat, "Aerodynamic noise computation of the flow field around NACA 0012 airfoil using large eddy simulation and acoustic analogy," Journal of Computational Applied Mechanics, vol. 46, no. 1, pp. 41-50, 2015.

[25] C.-S. Liu and C.-W. Chang, "A simple algorithm for solving Cauchy problem of nonlinear heat equation without initial value," International Journal of Heat and Mass Transfer, vol. 80, pp. 562-569, 2015.

[26] K. Cui and T. Zhao, "Unsaturated dynamic constitutive model under cyclic loading," Cluster Computing, pp. 1-11, 2017.

[27] J.-L. Zhang, J.-F. Yuan, J. Wan et al., "Efficient parallel implementation of incompressible pipe flow algorithm based on SIMPLE," Concurrency Computation, vol. 28, no. 6, pp. 17511766, 2016.

[28] S. Lorenzi, A. Cammi, L. Luzzi, and G. Rozza, "POD-Galerkin method for finite volume approximation of Navier-Stokes and RANS equations," Computer Methods Applied Mechanics and Engineering, vol. 311, pp. 151-179, 2016.

[29] Z. Li, J. Xue, P. Chen, L. Chen, S. Yan, and L. Liu, "Prevalence of nonalcoholic fatty liver disease in mainland of China: a metaanalysis of published studies," Journal of Gastroenterology and Hepatology, vol. 29, pp. 42-51, 2014.

[30] J. Huang, C. Zhang, S. Xiang, and et al., "Computation of aerodynamic noise radiated from open propeller using boundary element method," CMES, Computer Modeling in Engineering Sciences, vol. 108, no. 5, pp. 315-330, 2015.

[31] H. Yao, H. Zhang, H. Liu, and W. Jiang, "Numerical study of flow-excited noise of a submarine with full appendages considering fluid structure interaction using the boundary element method," Engineering Analysis with Boundary Elements, vol. 77, pp. 1-9, 2017.

[32] J.-S. Kim, U.-C. Jeong, J.-H. Seo, Y.-D. Kim, O.-D. Lee, and J.-E. $\mathrm{Oh}$, "Noise reduction of dry vacuum pump using the boundary element method to model impeller blade passage frequency," Applied Acoustics, vol. 93, pp. 51-64, 2015.

[33] J. Chen, Y. He, L. Gui, C. Wang, L. Chen, and Y. Li, "Aerodynamic noise prediction of a centrifugal fan considering the volute effect using IBEM," Applied Acoustics, vol. 132, pp. 182190, 2018. 


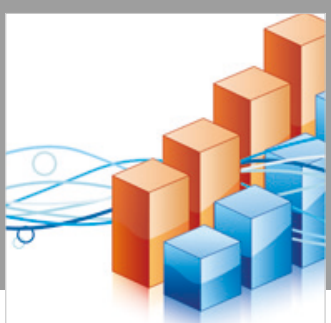

Advances in

Operations Research

\section{-n-m}
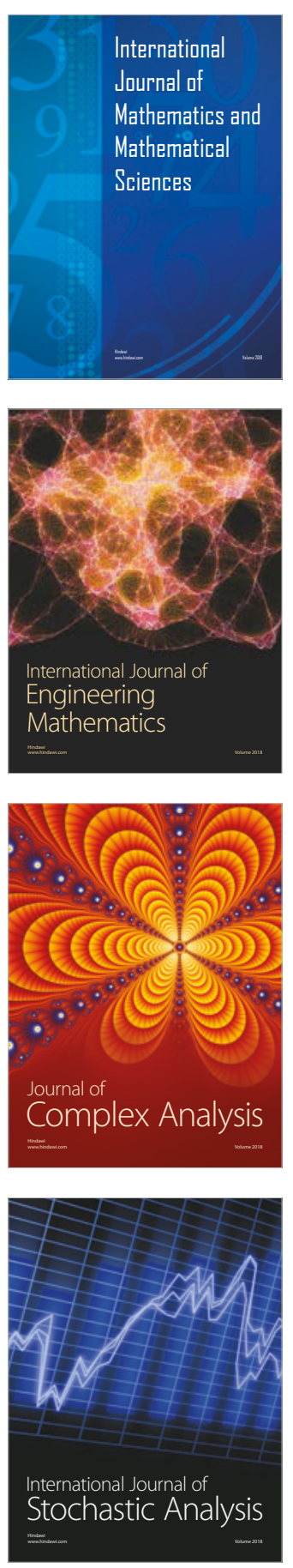
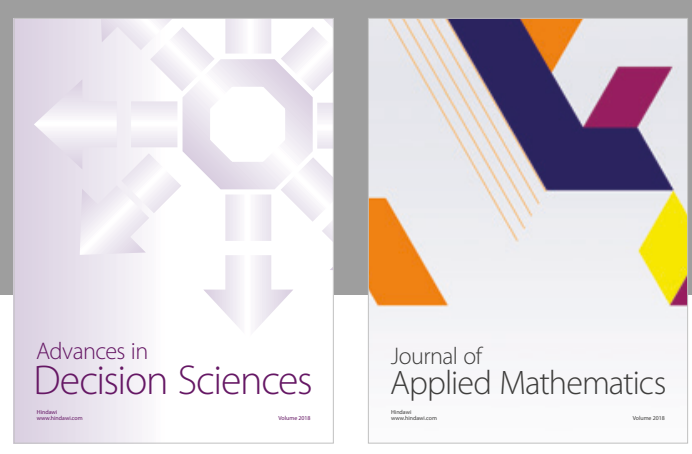

Journal of

Applied Mathematics
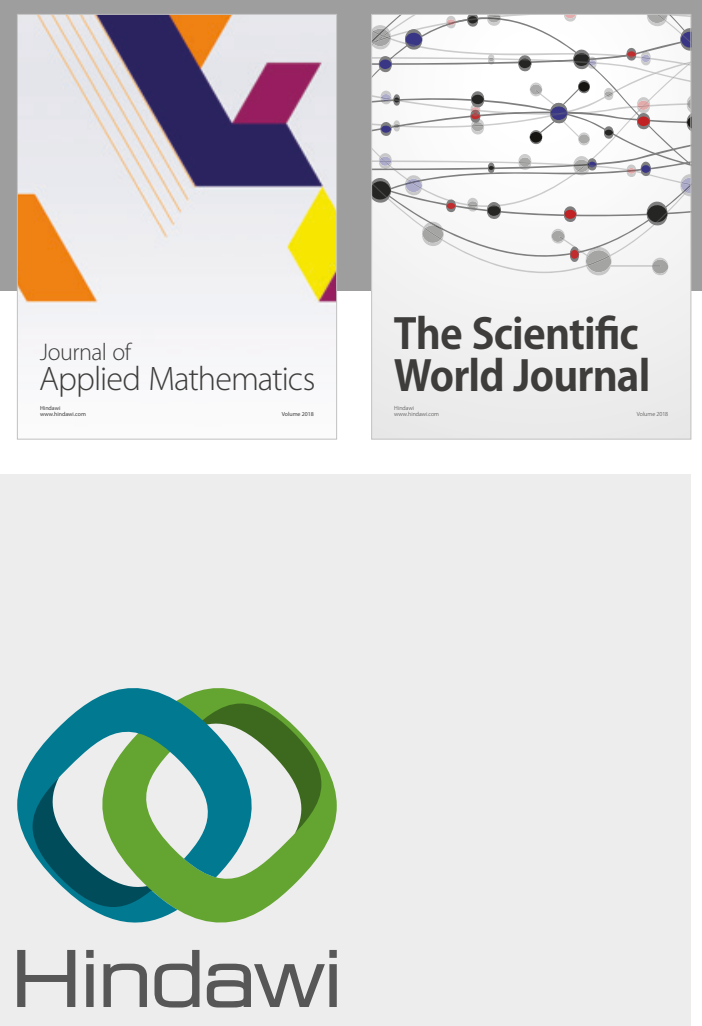

Submit your manuscripts at

www.hindawi.com

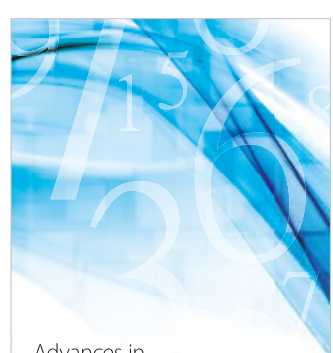

Advances in
Numerical Analysis
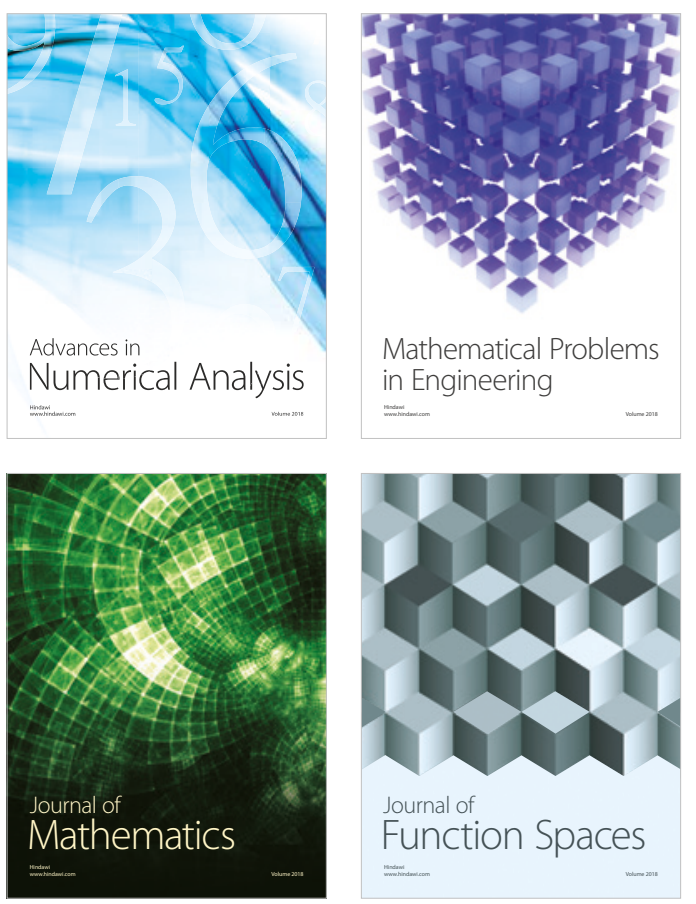

Mathematical Problems in Engineering

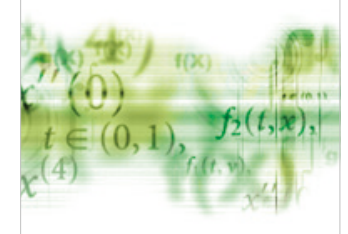

International Journal of

Differential Equations

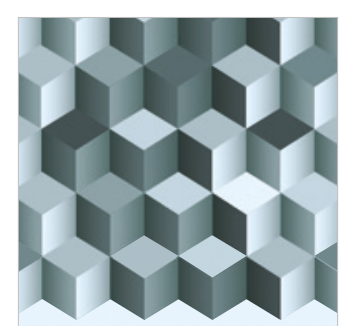

Journal of

Function Spaces
The Scientific

World Journal

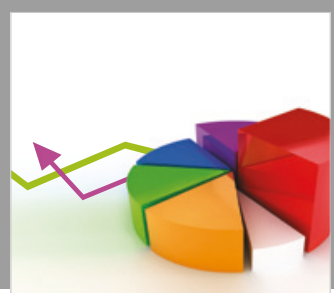

Journal of

Probability and Statistics
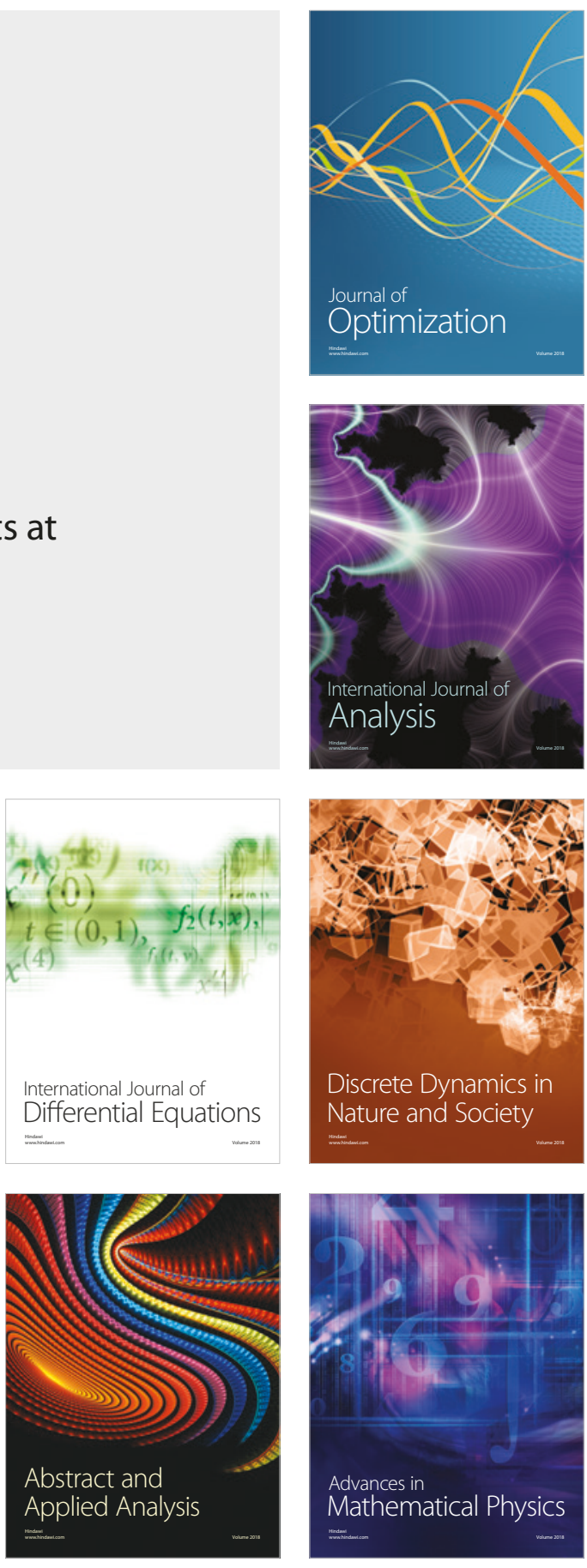